Review

\title{
Regio- and Stereospecific Analysis of Triacylglycerols-A Brief Overview of the Challenges and the Achievements
}

\author{
Svetlana Momchilova * and Boryana Nikolova-Damyanova
}

Institute of Organic Chemistry with Centre of Phytochemistry, Bulgarian Academy of Sciences, 1113 Sofia, Bulgaria; boryana.damyanova@gmail.com

* Correspondence: Svetlana.Momchilova@orgchm.bas.bg; Tel.: +359-2960-6135

\begin{abstract}
The efforts to reveal, in detail, the molecular and intramolecular structures of one of the main lipid classes, namely, triacyl-sn-glycerols, which are now known to affect their specific and important role in all living organisms, are briefly overviewed. Some milestones of significance in the gradual but continuous development and improvement of the analytical methodology to identify the triacylglycerol regio- and stereoisomers in complex lipid samples are traced throughout the years: the use of chromatography based on different separation principles; the improvements in the chromatographic technique; the development and use of different detection techniques; the attempts to simplify and automatize the analysis without losing the accuracy of identification. The spectacular recent achievements of two- and multidimensional methods used as tools in lipidomics are presented.
\end{abstract}

Keywords: triacylglycerols; regioisomers; enantiomers; chromatography; mass spectrometry; HPLC

check for

updates

Citation: Momchilova, S.; Nikolova-Damyanova, B. Regioand Stereospecific Analysis of Triacylglycerols-A Brief Overview of the Challenges and the Achievements. Symmetry 2022, 14, 247. https:// doi.org/10.3390/sym14020247

Academic Editors: Yutaka Itabashi and Stefano Superchi

Received: 20 October 2021

Accepted: 9 December 2021

Published: 27 January 2022

Publisher's Note: MDPI stays neutral with regard to jurisdictional claims in published maps and institutional affiliations.

Copyright: (c) 2022 by the authors. Licensee MDPI, Basel, Switzerland. This article is an open access article distributed under the terms and conditions of the Creative Commons Attribution (CC BY) license (https:// creativecommons.org/licenses/by/ $4.0 /)$.

\section{Introduction}

Triacylglycerols (TAGs further in the text), or triglycerides (as they were denoted previously), or triacyl-sn-glycerols (as they are denoted more correctly at present), consist of a glycerol moiety in which the three hydroxyl groups (-OH further in the text) are esterified with fatty acids (FAs). Triacylglycerols are the main and most abundant class of simple lipids, denoted as simple because they yield two types of primary products per molecule in hydrolysis: glycerol and fatty acids [1]. The need to know, in detail, the TAG molecular and intramolecular structures is determined by their specific role in the life of plants, animals and humans: (i) TAGs are the main component of natural oils and fats of plant and animal origin, including all edible oils [1]; (ii) TAGs are one of the main energy sources for living organisms [2]; (iii) TAGs are the most important source of FAs that are essential for human health [3]; (iv) the intramolecular structure of TAGs strongly influences both the digestibility and metabolism of dietary FAs [4]. On the other hand, the TAG composition of plants is impacted by cultivar, harvest period and geographical origin [5-8], while that of animals depends on feeding as well $[9,10]$. Thus, the detailed examination of the TAG molecular structure has always been one of the main tasks of lipid analysis. The problem that the analysis faces is that since natural TAGs are produced by enzymatic synthesis, a center of asymmetry exists at position 2 [11] (Figure 1), while, in addition, each of the three -OH groups might be esterified by a different FA. Indeed, in most fats and oils, FAs are usually limited to the 20 most abundant in nature (out of the approximately 1000 described as yet [11]), but even these are of different chain lengths, might have different numbers, positions and configurations of double bonds and may esterify any of the - $\mathrm{OH}$ groups, leading to the formation of a spectacular number of TAG species in many natural lipids (consider milk fat, fish oil, other marine organisms or bacteria, for example). Thus, depending on the FA structure and position on the glycerol backbone, the simple lipid class of TAGs presents a number of different structures, including regioisomers and/or enantiomers, creating a serious challenge for efforts aimed at determining their molecular and intramolecular structures. 


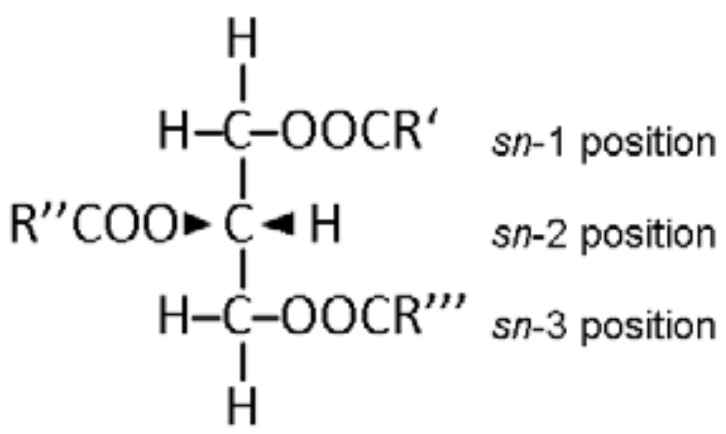

Figure 1. The Fischer projection of triacyl-sn-glycerol.

The interest in lipid analysis, and that of FAs and TAGs in particular, has a very long history, but the most important achievements were made in the middle of the 20th century [12]. Step by step, using the power of any new technique for separation, detection, identification and quantification that appeared resulted in the development of a number of analytical approaches in TAG analysis, allowing for examining, in more detail, their molecular and intramolecular structures [13-19] in efforts: (i) to obtain information that is as complete as possible on the TAG composition of natural oils and fats of plant/animal origin and better understand the pathways of TAG enzymatic synthesis and their role in biological systems; (ii) to expose and better understand TAGs' role in living organisms, including human health and diet; (iii) to produce special formulations, such as infant milk-like products, food additives and others; (iv) to control the process and the quality of edible oils and fats and unequivocally trace adulteration.

Looking back, it seems that the leading motivation in developing new approaches was to increase the efficiency of the resolution and, mostly, to simplify the rather complicated TAG analysis as much as possible by cutting down as many analytical stages as possible and automatizing the analytical procedure. However, at present, one still has to examine, in detail, the FA composition as the first stage of a reliable determination of TAG molecular/intramolecular structures. Having this in mind, here, we briefly review the achievements of the analytical approaches for regio- and stereospecific analysis of TAGs.

The references cited here are only part of the papers dedicated to the topic, and the review has no pretention to be comprehensive. Efforts were made to show the milestones in the regio- and stereospecific analysis of TAGs while not forgetting that the problem has been discussed since the very early stage of lipid analysis in the middle of the 20th century, and that the principles used now in approaches denoted as two-dimensional, multidimensional, orthogonal, etc., were developed and suggested in those days.

\section{Regiospecific Analysis}

The $s n$-TAGs that differ in the FA composition between the $s n-1$ and $s n-2$ positions, or between the $s n-1$ (3) and $s n-2$ positions, are denoted as regioisomers. Their determination was the first, and probably the easiest, step in the examination of TAG intramolecular structures. The large number of analytical methods developed thus far can be divided into two major groups in general: (i) indirect approaches, i.e., methods using a preliminary degradation step by either enzymatic hydrolysis or with a Grignard reagent (ethylmagnesium bromide), followed by isolation of partial acylglycerols (all possible di- and mono-acylglycerols) by a normal-phase chromatographic procedure, silica gel thin layer chromatography (TLC), silica gel column (CC) or solid phase extraction (SPE), followed by gas chromatographic determination of the FAs and reconstructing the regioisomers; (ii) direct approaches (conditional), i.e., chromatographic, mass spectrometric (MS) or nuclear magnetic resonance (NMR) procedures based on certain specific characteristics of the molecular composition of the regioisomeric TAG. Note, however, that MS and NMR are indirect methods requiring reconstruction of the initial molecule based on a specific instrumental response. 


\subsection{Enzymatic Hydrolysis}

Historically, this was the first approach to provide information on regioisomeric TAGs, and the method was published as early as 1965 by Brockerhoff [20,21]. Pig pancreatic lipase was used since it appeared to be specific to hydrolyze the ester bonds at positions $s n-1$ and -3 in the molecule, producing a 2-monoacylglycerol whose FA composition was then easily determined. This procedure is multi-staged and has certain limitations due to the rate of hydrolyzation of the FAs. It works well with TAGs of common plant or animal origin since all straight-chain saturated FAs are hydrolyzed by the same rate irrespective of the chain length. Short-chain saturated FAs, such as those in milk TAGs (such as butyric acid), however, hydrolyze more rapidly, while long-chain polyunsaturated FAs (such as those in fish oil or marine lipids) hydrolyze more slowly. Many variations of this approach have been developed since the one suggested by Brockerhoff in 1965, but at the core, the procedure is, in general, the same as that shown by Christie [22]. The procedure that is most frequently used is described in detail in [23]. Other lipases have been used for the same purpose such as Rhizopus arrhizus (family Mucoraceae), but they have not shown any substantial advantages thus far [1].

\subsection{Chemical Methods}

Hydrolysis with a Grignard reagent—ethyl magnesium bromide [24] or allyl magnesium bromide [25] - is also a multi-stage procedure. Here, it is essential to stop the reaction before completion, which is advisable at $50 \%$ hydrolysis. TLC on silica gel G plates, impregnated with boric acid, is applied to isolate the various partial $s n$-acylglycerols: 1,2-, 2,3- and 1,3-diacyl-sn-glycerols (DAGs), and 1-, 2- and 3-monoacyl-sn-glycerols (MAGs), followed by isolation, determination of FAs and calculations to determine their position in the glycerol backbone (for example, [26] presented details of one of the published analytical protocols).

Grignard hydrolysis has been used as a first step in many other procedures aiming to determine the regioisomeric TAGs $[27,28]$.

\subsection{Chromatography}

Chromatography is an analytical tool that advanced lipid chemistry and led to an incomparable better understanding of the very complex mixture of natural TAGs. Performed in different forms: as a layer or column of a silica adsorbent pre-treated with different reagents in order to modify or change the functionality and increase the selectivity of the separation power, combined with new effective methods of detection, automatized and computerized, this technique allowed for looking inside the TAG molecular and, later, intramolecular structure. All chromatographic techniques developed since the middle of the 20th century have been applied in TAG analysis, and many allow for the determination of their composition in a large number of natural plant and animal lipids of terrestrial and marine origin. Of these, silver ion and reversed-phase liquid chromatography techniques were, and still are, the most successfully used, and the procedures developed thus far easily resolve and unambiguously identify TAG regioisomers, i.e., determination of these isomers is no longer a problem for lipid chemists of common oils and fats [17,19].

\subsubsection{Silver Ion Thin-Layer Chromatography (Ag-TLC)}

A significant amount of research has been reported and discussed regarding the chemical processes that lay the fundament of this technique [29-33], which is forgotten or rarely used now, not because it provides less reliable results for common fats and oils, but mostly because it requires more laborious laboratory work in order to compensate for the much lower efficiency of the TAG resolution. Briefly, the separation of TAGs is based on a distinctive property of unsaturated organic compounds-FA moieties in this case-to form weak reversable charge-transferred complexes with silver ion, $\mathrm{Ag}^{+}[33,34]$. Thus, $\mathrm{Ag}^{+}$ chromatography allows resolving TAGs in the order of general unsaturation, with those that are most saturated migrating first. In addition, it is possible to easily differentiate between such regioisomeric pairs as SMS/SSM, SMM/MSM, SDS/SSD, MDM/MMD, 
SDD/DSD and MDD/DMD (S, M and D stand for saturated, monoenoic and dienoic FA moieties; in each pair, the first TAG migrates ahead) [29,30,34-36]. The technique consists of the application of the TAG sample as a band on an impregnated plate, which, in turn, is developed in a closed or open tank with a defined volume of the mobile phase. If required, the plate is dried, and the development is repeated with the same or another mobile phase. It is also possible to apply the sample on two or more different plates, developing each separately with different mobile phases to obtain the desired resolution. Details of the analytical procedures can be found in $[30,32,37]$.

Historically, the first achievement in the separation of regioisomeric TAGs was demonstrated by Blank et al. as early as 1965 [35], i.e., three years after silver ion chromatography, both as the thin layer and column techniques, was introduced for the first time in the practice of lipid analysis, allowing for separation of TAG molecular species. In both cases, silica gel $\mathrm{G}$, used as a carrier, was impregnated with $0.5-10 \% \mathrm{AgNO}_{3}$ in methanol, and mixtures of chloroform-methanol and $n$-hexane (petroleum ether)-acetone of different proportions (to name only the most frequently used) were employed as mobile phases. Procedures to quantify the TAG composition by different direct and indirect approaches have been developed, with densitometric scanning of the plate providing accurate results concerning the relative content of each TAG class [30]. The qualitative and quantitative results were usually confirmed by gas chromatographic determination of the respective FA composition. It should be stressed that a large number of common fats and oils of different origin, as well as TAGs in plant and animal tissues and organs, have been studied by employing this tedious, time-consuming technique, and the information collected, while not being as detailed as that provided by later techniques, is undeniably correct. By using Ag-TLC to resolve and identify regioisomeric TAGs, it has been possible to detect adulteration in cocoa butter [38] and olive oil [39] (note the publication years). More information about these early techniques, including quantification approaches, can be found in $[1,30,31,33]$.

\subsubsection{Silver Ion High-Performance Liquid Chromatography (Ag-HPLC)}

Once Christie [40] published the simple effective procedure to load $\mathrm{AgNO}_{3}$ on a commercial HPLC Nucleosil silica gel column, Ag-TLC was almost completely replaced by Ag-HPLC in studying the TAG composition of lipids. Among the other advantages, using HPLC allowed connecting columns in series [41] and applying gradient elution, thus significantly increasing the efficiency of the TAG resolution and clearly resolving species such as various regioisomers [41-45]. The published procedures used $10 \% \mathrm{AgNO}_{3}$ to load the column, and a complex solvent gradient of either acetonitrile [41,42] or ethylacetate $[44,46]$ in $n$-hexane $[41,42,46]$ or toluene $[43,44]$ for resolution of regioisomeric TAGs in relatively simple samples such as cocoa butter or palm oil. Later, it was possible to work with commercial silver-loaded ChromSpher Lipids columns. In addition, it was technically possible to connect the column to one or more detectors, working on different principles: ultraviolet (UV), refractive index (RI), flame ionization (FID), evaporative light scattering (ELSD), and especially series of mass detectors: electrospray ionization (ESI), atmospheric pressure chemical ionization (APCI), thus gaining more information in a single run $[1,15,32-34,37,45,47,48]$. The analytical protocols presented in these references describe, in detail, all analytical stages. The pairs SMS/SSM, SDS/SSD, SMM/MSM and SDM/SMD/MSD were resolved (i.e., the same pairs as those in Ag-TLC; notation of FA moieties is the same as above). To the best of the authors' knowledge, thus far, only Adlof [41,42], using two home-made columns connected in series, isocratic elution and UV detection, and Holcapek et al. [45,49], using three ChromSpher Lipids columns connected in series, gradient elution and an APCI-MS detector, were able to resolve and identify regioisomeric TAG pairs containing trienoic FAs. Thus, the resolution of the pairs SOS/SSO, SOO/OSO, SLnS/SSLn, SLnO/SOLn/OSLn, OLnO/OOLn, SLnLn/LnSLn and OLnLn/LnOLn (S, saturated; O, oleic; Ln, linolenic acid moieties) was demonstrated [49].

The FID, ELSD and APCI/ESI detection techniques allow for semiquantitative estimation of the relative TAG content in the sample. For a correct quantification, the detector 
should be calibrated against an external or internal standard, the latter requiring both a generic relation to and perfect separation from the components in the sample [50].

At this stage, it appears that Ag-HPLC while providing almost the same resolution of regioisomeric TAGs outstages Ag-TLC in achieving the results in shorter elution time with by far higher accuracy and precision. The disadvantage of Ag-HPLC is the tedious work to prepare a home-made silver-loaded column and the relatively short life (several months) of the commercial columns.

\subsubsection{Reversed-Phase High-Performance Liquid Chromatography (RP-HPLC)}

For many reasons, most of which are out of the scope of this review, another separation technique, which was firstly developed in TLC mode as well, has gained very wide and dominating application in TAG analysis-high-performance liquid chromatography, which uses columns packed with silica gel particles of different sizes with bonded octyl- (C8) or octadecylsilane (ODS or C18 columns) moieties and mixtures of polar solvents as a mobile phase. This technique is denoted as either reversed-phase liquid chromatography, RP-HPLC, or, more correctly in the case of TAG separation, non-aqueous reversed-phase liquid chromatography (NARP-LC). In brief, TAGs are separated according to their equivalent carbon number $(\mathrm{ECN})$ which represents their general polarity-a combination of the number of carbon atoms (NCA) and the number of double bonds (NDB), i.e., $\mathrm{ECN}=\mathrm{NCA}-2 \mathrm{NDB}$, in the acyl chains, with a TAG retained as strongly as higher is the respective $\mathrm{ECN}$ (i.e., the higher the number of carbons, the lower the number of double bonds in the acyl chains) $[13,19,51-55]$. Moreover, the book chapter [52] and the literature cited therein presented some aspects of the mechanism of retention and separation in RPHPLC of TAGs. The efficient combination of a complex elution gradient with mobile phases based on (mainly) acetonitrile modified with dichloromethane, 2-propanol or $n$-hexane (as a stand-alone solvent or in mixtures) with RI, ELSD or a mass detector (positive/negative CI, ESI and APCI [1,19]) allowed for clear differentiation of TAGs according to the chain length of FA moieties and the position and configuration of double bonds in the chains and definitely allowed gaining significantly more information on the TAG composition in natural oils and fats. Evidence was found that the FA moieties at position 2 might affect the resolution of regioisomers [56], and, indeed, a complete simultaneous regioselective separation of ten isomeric triacylglycerols in a single isocratic run on a single C18 column was demonstrated [57]. Separation and determination of isomeric TAGs in natural TAG samples, however, have not been achieved, and it seems that the efforts to further explore this possibility were abandoned. As above, detection with ELSD and MS allows for estimating only the relative quantity of the components.

Later, it was demonstrated that an indirect method based on the specific fragmentation pattern of TAG species in mass spectrometry might be very fruitful in identifying and quantifying TAGs in general and regioisomeric TAGs in particular. It appeared possible to identify regioisomers by using mass detectors and reconstructing their structure by analyzing the fragmentation in their mass spectra. This approach was based on the relative intensities of the [M-RCOO] ${ }^{+}$ions which were shown to depend on the position of FA moieties in the molecule [58-60]. More information on the principles and application is presented in [61-63]. APCI is most frequently used for the purpose, and TAG regioisomers in a large number of plant oils [60,64-67], algae [68,69], fish oils [70], bacteria [71-73], yeasts [74] and insects [75] have been identified. The importance of the chromatographic resolution to correctly identify the TAG composition was understood, and efforts were directed to improving the reconstruction, by improving the chromatographic step either by testing the properties of the stationary phase [57] or by elongating the chromatographic "path" through connecting two columns in series [76,77].

The efficiency of ESI in TAG analysis has been discussed in detail in [1] (part 5), including the efficiency in the quantification of molecular species. ESI was used to examine the retention behavior of TAGs in RP-HPLC [78], to determine regioisomeric TAGs containing branched-chain FAs (tandem positive ESI) [79] and for identification of TAG regioisomers 
in lard, tallow, yolk, chicken skin, palm oil, palm olein, palm stearin and trans-esterified blends of palm stearin and coconut (tandem negative ESI) [80], in milk [81] and in fish oil (triple-stage ESI) [82].

Quantification of TAG species in RP-HPLC/MS has been thoroughly discussed, and the need for careful calibration has been clearly exposed $[64,76,77,83]$.

\subsubsection{Combined Chromatographic Methods}

As discussed above, even the simple natural oils and fats, where TAGs are the main lipid component and the FA composition is limited to 4 or 5 straight-chain FAs with 16 to 18 carbon atoms and 0 to 3 double bonds, might form a large number of molecular species, presenting problems for their identification and quantification. The problems increase when it comes to studying TAGs in more complicated natural sources such as milk fat and fish oils in marine organisms and are further multiplied when a detailed TAG analysis is engaged in lipidomics [1]. To answer these challenges, lipid analysis turned back to the well-exploited combination of normal-phase, silver ion and non-aqueous reversed-phase high-performance liquid chromatography, i.e., it went back to the classical approach of successive application of separation techniques based on different separation principles. The successive separation stages simplified the TAG mixture to fractions with preliminary defined molecular characteristics (such as the unsaturation level and polarity) for further high-resolution mass detection, thus allowing for a better reconstruction of their intramolecular structure and quantification. At present, the online or offline connection of two or more chromatographic columns, which should be "orthogonal" (i.e., should use different separation principles such as Ag- and NARP-LC), is known as two-dimensional chromatography or is denoted as multidimensional chromatography in the case where additional preliminary steps are employed [84-88]. Note that the principles and opportunities of two-dimensional chromatography were presented nearly a decade ago [89,90]. Combining chromatography with enzymatic degradation and efficient mass detection allowed determining TAG regioisomers including those in complex and very complex samples, such as rice oil [91] and bacteria [79,92]. In most of the recent works where two- or multidimensional orthogonal chromatographic approaches and powerful high-resolution mass detection were used, the determination of regioisomers was part of the detailed stereospecific analysis of TAGs in lipids; examples are shown below.

\subsubsection{Other}

Besides the most widely used approaches shown above, occasionally other methods have been used as well, and some examples are briefly mentioned here. GC on a $25 \mathrm{~m} \times 0.25 \mathrm{~mm}$ i.d polarizable phenyl(65\%)-methylsilicone capillary column with a $0.1 \mu \mathrm{m}$ film thickness combined with Ag-HPLC allowed for spectacular separation of series of butyrate and caproate regiosomers in esterified butter oil: 4:0/14:0/16:0-14:0/4:0/16:0; 6:0/14:0/16:0-14:0/6:0/16:0; 4:0/16:0/16:0-16:0/4:0/16:0; 4:0/14:0/18:0-14:0/4:0/18:0; 6:0/16:0/16:0-16:0/6:0/16:0; 6:0/14:0/18:0-14:0/6:0/18:0; 4:0/16:0/18:0-16:0/4:0/18:0; 6:0/16:0/18:0-16:0/6:0/18:0; 4:0/18:0/18:0-18:0/4:0/18:0, eluting in this order [17]. Supercritical fluid chromatography (SFC) has also been explored [93-96], and it is claimed that when coupled with mass detectors, SFC ensures a good identification of regioisomeric TAGs separated for shorter times than with HPLC under identical conditions. Thus, sn$\mathrm{POO} / \mathrm{OPO} / \mathrm{OOP}$ were separated by SFC coupled with a triple quadrupole mass spectrometer (SFC/MS/MS) using a CHIRALPAK ${ }^{\circledR}$ IG-U column with acetonitrile and methanol in the mobile phase (for example, [97]) for only $40 \mathrm{~min}$, while $50 \mathrm{~min}$ was required for the resolution of PPLn/PLnP, PPL/PLP, PPO/POP, SPLn/SLnP, SPO/SOP and SSO/SOS pairs in palm and canola oils by SFC-positive ESI [98]. 


\subsection{Spectrometry}

\subsubsection{Mass Spectrometry (MS)}

Mass spectrometry has been used in combination with other techniques besides chromatography. In fact, MS was applied as a single method for TAG analysis as early as the 1960 when Ryhage and Stenhagen observed that loss of acyloxymethylene in mass spectra occurred from positions 1 and 3 and not from position 2 of the glycerol moiety, which allowed for recognizing regioisomers [99]. The authors noted that further experimental work was necessary before such assignments could be made with any degree of confidence. Over the years, this observation was confirmed for all MS techniques. Among the most frequently used modes is ammonia-negative ion chemical ionization (NICI) tandem MS developed in the early 1990s by Kallio and Currie $[100,101]$ and gradually optimized for application in analysis of TAG regioisomers in various samples [102-106]. On the other hand, positive electrospray ionization (ESI) tandem MS with cationization by lithium ions has been applied in several laboratories for the same purpose with both pure standards $[107,108]$ and TAG fractions isolated from plant oils [109-113]. Atmospheric pressure chemical ionization (APCI) MS is another common technique for direct TAG analysis [59,114]. Byrdwell contributed to the method development by introducing the critical ratios for providing direct structural information for isomeric TAGs, and by creating a compact library of TAG mass spectra [115-117]. Two comprehensive reviews summarized the results of the sole use of mass spectrometry to resolve intramolecular TAG structures [17,118], and, indeed, direct MS was applied successfully in some cases such as in milk [119] and salmon fish [120]. An approach to determine the ratio of regioisomeric TAGs by direct ESI analysis was suggested in [121].

\subsubsection{Nuclear Magnetic Resonance Spectrometry (NMR)}

The efforts to use ${ }^{13} \mathrm{C}$ NMR for TAG analysis can be traced back to the 1990s [122,123], and NMR has been applied to identify the intramolecular structure of TAGs in olive oil [124] and tissues [125]. It seems that NMR is especially productive in studying milk TAGs and in controlling the production quality of structured lipids in infant formula through the ability to recognize the presence of certain TAG isomers [126,127]. The utilization and achievement of this technique were recently reviewed by Indelicato et al. [19].

Separate attention should be paid to the use of high-resolution techniques such as mass spectrometry and nuclear magnetic resonance spectrometry to directly determine the intramolecular TAG structure in biological samples, omitting the separation step. This approach currently denoted as "shotgun lipidomics" is very attractive. Undoubtedly, its used for rapid detection, for example, of regioisomers-reporting the adulteration of edible or expensive natural fats and oils, such as olive oil [128]—should be welcome. The use of MS in the shotgun approach was recently reviewed $[129,130]$. Estimating whether the shotgun procedures are able to provide full and correct results for the TAG intramolecular structure in all varieties of samples, irrespective of the complexity of their composition, is a matter of the future.

\section{Stereospecific Analysis}

Stereospecific analysis of TAGs aims to determine the FA moieties in each position $(s n-1,-2,-3)$ in the glycerol backbone, i.e., to present, in full, the real intramolecular structure of each TAG in the lipid sample. As discussed above (Sections 2.1 and 2.2), the classical enzymatic [20] or Grignard procedures to partially hydrolyze TAGs, followed by series of derivatization and separation steps of the produced partial acylglycerols, allow for determining the intramolecular $s n-1,-2$ and -3 structures of species. As shown, these procedures have certain limitations due to the structure of the FA moieties, and, in addition, they are multi-staged, laborious and time consuming and require well-skilled staff. The further development of HPLC techniques and the introduction of chiral columns in the analytical practice have allowed for alternative approaches: (i) separation on achiral stationary phases of $s n$-TAGs via diastereomeric diacylglycerol derivatives, and (ii) resolution 
on chiral stationary phases of diacylglycerol or monoacylglycerol derivatives and, lately, of intact TAGs.

The first procedure includes partial chemical hydrolyzation of TAGs, and derivatization of the resulting $s n-1,2(2,3)-$ and 1,3-DAGs, with the chiral reagent (S)-(+)-1-(1naphtyl)ethyl isocyanate separating the diacyl-sn-glycerol derivatives on the achiral stationary phase in the silica gel column $[55,131]$. Takagi and Itabashi, followed later by Ando and co-workers, explored the second approach: producing either sn-MAG isomers [132-134] or sn-DAG isomers [28,135-141] by Grignard hydrolysis of the TAGs, derivatization of the DAGs or MAGs to 3,5-dinitrophenyl urethane (DNPU) derivatives and resolving these by HPLC in chiral columns. Other derivatives with the same properties and with strong UV or fluorescent absorption such as 2-anthrylurethanes were also found to be suitable for the purpose [142]. This approach was applied for the determination of TAG intramolecular structures in samples such as milk fat [28] and fish oil [143]. The methodology and detailed analytical protocols were reviewed in $[16,66,144,145]$. The problem in widely using this fruitful and correct semidirect approach for stereospecific TAG analysis is due to the rather complicated and expensive stationary phases in which chiral reagents such as N-(S)-2-(4-chlorophenyl)isovaleroyl-D-phenylglycine (Sumipax OA-2100, Sumitomo Chemical Co., Tokyo, Japan) or N-(R)-1-(alpha-naphthyl)ethylaminocarbonyl-(S)-valine (Sumipax OA-4100) are chemically bonded to gamma-aminopropyl silanized silica.

Inevitably, efforts were next focused on simplifying the analysis, and the obvious step was to search for conditions to resolve intact TAGs by chiral HPLC. Thus, various chiral stationary phases were developed along with wide application of two- or multidimensional approaches as described above-stepwise simplification of TAG mixtures by application of silver ion or reversed-phase HPLC as stand-alone or successive separation techniques. The key role in these approaches was played by high-resolution tandem MS for detecting and identifying TAG isomers. Ten years ago, Nagai and co-workers [146] tested several chiral columns (CHIRALPAK IA, IB, IC, AD-RH, AS-RH, AY-H, CHIRALCEL OD-RH, OJ-RH and OZ-H) based on polysaccharide derivatives coated or immobilized on silica gel for normalphase or reversed-phase HPLC. Promising results were achieved with the CHIRALCEL OD-RH column which could resolve racemic mixtures of asymmetric TAGs, containing palmitic, oleic and linoleic acyl residues. This new chiral separation method in combination with APCI-MS was capable of determining the ratio of $s n$-OOP to $s n-\mathrm{POO}$ in palm oil, and this was the first report of the separation of enantiomeric asymmetric natural TAGs. This analytical protocol was also applied for the analysis of TAGs in marine organisms [147] and bovine milk fat [148], and for the investigation of asymmetric TAGs [149]. Using the same system of recycling HPLC and connecting two chiral columns in series, Kalpio and co-workers separated enantiopure reference compounds of eleven racemic TAGs containing C12-C22 FAs with 0-2 double bonds [150], or omega-3 polyunsaturated FAs [151], and determined the isomers in sea buckthorn as an example food matrix [88]. Nagai and co-workers, using a CHIRALPAK IF-3 column, examined the separation of various TAG isomers and recommended this variant of chiral column as especially applicable for the analysis of the TAG composition of semi-solid fats such as palm oil [152,153]. A variation of this chiral phase (CHIRALPAK IG-U column) was applied by Masuda et al. [97] for the first report of simultaneous and rapid analysis of TAG regioisomers and enantiomers using SFC. The method was used to quantify $s n-\mathrm{OPO}, s n-\mathrm{POO}$ and $s n-\mathrm{OOP}$ in extra virgin olive oil, refined olive oil, palm oil, palm olein and interesterified palm olein. Two Lux Cellulose- 1 columns connected in series and combined with an APCI-MS detector allowed for the systematic investigation of TAG enantiomers in real samples of hazelnut oil and human plasma [154]. Thus, it was possible to determine all TAG enantiomers with acyl chains of different lengths and one to eight double bonds, except the TAG species with saturated, dienoic and/or trienoic FA moieties at the $s n-1$ and $s n-3$ positions. Applying the two- or multidimensional approach, it appeared possible to obtain more accurate information for TAGs with more complicated structures and in more complicated lipids. Chen et al. [155] determined isomeric TAGs in human milk by preliminary fractionation 
of the TAGs by RP- and Ag-HPLC followed by separation on the same Lux Cellulose-1 column. In their work studying TAG isomers in complex lipids, Rezanka and co-workers employed two Astec CYCLOBOND ${ }^{\mathrm{TM}}$ I 2000 3,5-dimethylphenyl carbamate-modified $\beta$-cyclodextrin chiral columns combined with high-resolution MS detection. TAGs with FA moieties of various types were first fractionated by the RP-HPLC stand-alone method, or combined with silver ion chromatography. Using this multidimensional approach, the research team was able to identify both regio- and stereoisomeric TAGs in diatom Phaeodactylum tricornutum (family Phaeodactylaceae) [72], in different Stichococcus strains (family Prasiolaceae) [73], in yeasts of seven genera [74], in nine cultivated strains of microalgae from different taxonomic groups [156], in protozoan and mold [157] and in the haptophyte alga Coccolithophora sp. [158], as well as TAGs with very long chain fatty acids [159], with branched fatty acids (iso and/or anteiso) [79], with cyclofatty acids [160] or with allenic and acetylenic fatty acids [161].

The scheme in Figure 2 [162] illustrates the essence of the multidimensional analytical protocol which includes a detailed examination of the FA composition, and steps to reveal, as fully as possible, the TAG molecular and intramolecular structures. Evidently, this approach is the one that, at present, provides the information needed for better understanding the role of the TAG structure (i.e., the exact position of FA moieties in the glycerol backbone) in the metabolism pathways in biological systems [163].

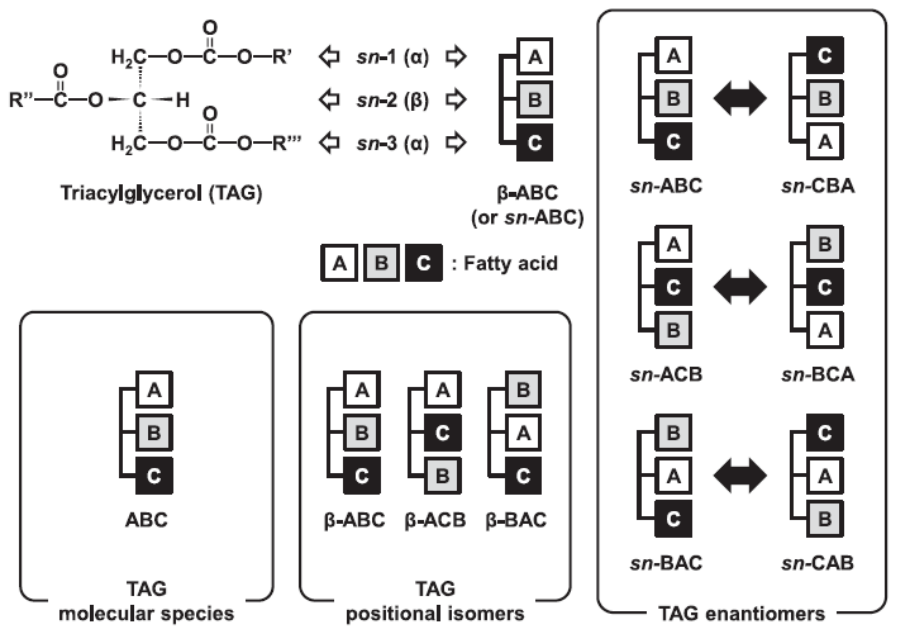

Figure 2. Determination of TAG molecular and intramolecular structures. Adapted with permission from Ref. [162]. Copyright 2021 Svetlana Momchilova.

\section{Concluding Remarks}

Efforts were made in this brief review to present the development in the analysis of TAGs in the last 70 years in pursuing the aim to determine, as fully as possible, their structure. The contributions of all widely used separation and identification techniques such as chromatography, mass spectrometry and nuclear magnetic resonance were presented, followed by their application, and some of their best achievements were explored. This review shows the readiness of the lipid community throughout the years to use all methodological novelties and all improvements to reveal, as fully as possible, the TAG molecular and intramolecular structures of plant and animal origin, thus helping to better understand their important role in living organisms.

Author Contributions: S.M. and B.N.-D. wrote, edited and revised the manuscript. All authors have read and agreed to the published version of the manuscript.

Funding: This research was funded by the Bulgarian National Science Fund, grant DN 19/14 from 12 December 2017.

Institutional Review Board Statement: Not applicable. 


\section{Informed Consent Statement: Not applicable.}

Data Availability Statement: Data supporting reported results are given in the references cited in this review.

Acknowledgments: S.M. thanks for the support from the Operational Program "Science and Education for Smart Growth" 2014-2020, cofinanced by the EU (Grant BG05M2OP001-1.002-0012).

Conflicts of Interest: The authors declare no conflict of interest.

\section{References}

1. Christie, W.W.; Han, X. Lipid Analysis: Isolation, Separation, Identification and Lipidomic Analysis, 4th ed.; The Oily Press: Bridgwater, UK, 2010.

2. Gunstone, F.D.; Harwood, J.L.; Padley, F.B. The Lipid Handbook, 1st ed.; Chapman and Hall: London, UK; New York, NY, USA, 1986.

3. Chow, C.K. Fatty Acids in Foods and Their Health Implications, 2nd ed.; Marcel Dekker: New York, NY, USA; Basel, Switzerland, 2000.

4. $\quad$ Michalski, M.C.; Genot, C.; Gayet, C.; Lopez, C.; Fine, F.; Joffre, F.; Vendeuvre, J.L.; Bouvier, J.; Chardigny, J.M.; Raynal-Ljutovac, K. Multiscale structures of lipids in foods as parameters affecting fatty acid bioavailability and lipid metabolism. Progr. Lipid Res. 2013, 52, 354-373. [CrossRef] [PubMed]

5. Giuffrè, A.M. Variation in triacylglycerols of olive oils produced in Calabria (Southern Italy) during olive ripening. Riv. Ital. Sost. Gr. 2014, 91, 221-240.

6. Giuffrè, A.M. Influence of cultivar and harvest year on triglyceride composition of olive oils produced in Calabria (Southern Italy). Eur. J. Lipid Sci. Technol. 2013, 115, 928-934. [CrossRef]

7. Herchi, W.; Trabelsi, H.; Ben Salah, H.; Zhao, Y.Y.; Boukhchina, S.; Kallel, H.; Curtis, J.M. Changes in the triacylglycerol content of flaxseeds during development using liquid chromatography atmospheric pressure photoionization-mass spectrometry (LC-APPI-MS). Afr. J. Biotechnol. 2012, 11, 904-911. [CrossRef]

8. Parcerisa, J.; Rafecas, M.; Castellote, A.I.; Codony, R.; Farràn, A.; Garcia, J.; López, A.; Romero, A.; Boatella, J. Influence of variety and geographical origin on the lipid fraction of hazelnuts (Coryllus avellana L.) from Spain: (II). Triglyceride composition. Food Chem. 1994, 50, 245-249. [CrossRef]

9. Perona, J.S.; Portillo, M.P.; Macarulla, M.T.; Tueros, A.I.; Ruiz-Gutiérrez, V. Influence of different dietary fats on triacylglycerol deposition in rat adipose tissue. Brit. J. Nutr. 2000, 84, 765-774. [CrossRef] [PubMed]

10. Garrido-Fernández, A.; León-Camacho, M. Effect of season, feeding, and anatomical region on the triacylglycerol profile of Iberian pig fat. Food Chem. 2021, 361, 130070. [CrossRef]

11. Scrimgeour, C.M.; Harwood, J.L. Fatty Acid and Lipid Structure. In The Lipid Handbook; Gunstone, F.D., Harwood, J.L., Dijkstra, A.J., Eds.; CRC Press: New York, NY, USA, 2007.

12. Hammond, E.W. Lipid analysis-A 20th century success? J. Sci. Food Agric. 2002, 82, 5-11. [CrossRef]

13. Laakso, P. Analysis of triacylglycerols-approaching the molecular composition of natural mixtures. Food Rev. Int. 1996, 12, 199-250. [CrossRef]

14. Kuksis, A.; Marai, L.; Myher, J.J. Strategy of glycerolipid separation and quantitation by complementary analytical techniques: Plenary lecture. J. Chromatogr. B 1983, 273, 43-66. [CrossRef]

15. Andrikopoulos, N.K. Chromatographic and spectroscopic methods in the analysis of triacylglycerol species and regiospecific isomers of oils and fats. Crit. Rev. Food Sci. Nutr. 2002, 42, 473-505. [CrossRef]

16. Kuksis, A.; Itabashi, Y. Regio- and stereospecific analysis of glycerolipids. Methods 2005, 36, 172-185. [CrossRef]

17. Kalo, P.J.; Kemppinen, A. Regiospecific analysis of TAGs using chromatography, MS, and chromatography-MS. Eur. J. Lipid Sci. Technol. 2012, 114, 399-411. [CrossRef]

18. Christie, W.W. Silver ion and chiral chromatography in the analysis of tricylglycerols. Prog. Lipid Res. 1994, 33, 9-18. [CrossRef]

19. Indelicato, S.; Bongiorno, D.; Pitonzo, R.; di Stefano, V.; Calabrese, V.; Indelicato, S.; Avellone, G. Triacylglycerols in edible oils: Determination, characterization, quantitation, chemometric approach and evaluation of adulterations. J. Chromatogr. A 2017, 1515, 1-16. [CrossRef]

20. Brockerhoff, H. A stereospecific analysis of triglycerides. J. Lipid Res. 1965, 6, 10-15. [CrossRef]

21. Brockerhoff, H. Stereospecific analysis of triglycerides: An alternative method. J. Lipid Res. 1967, 8, 167-169. [CrossRef]

22. Christie, W.W. Triacylglycerols 3. Regio- and Stereospecific Analysis of Triacyl-sn-glycerols. Available online: https://www. lipidmaps.org/resources/lipidweb/lipidweb_html/lipids/simple/tag3/index.htm (accessed on 10 March 2021).

23. Luddy, F.E.; Breadford, R.A.; Herb, S.F.; Paul, M.A. A rapid quantitative procedure for the preparation of methyl esters of butter, fat and other fats. JAOCS 1968, 45, 549-552. [CrossRef]

24. Ando, Y.; Tomita, Y.; Haba, Y. Preparation of ethyl magnesium bromide for regiospecific analysis of triacylglycerols. J. Oleo Sci. 2008, 57, 459-462. [CrossRef]

25. Becker, C.C.; Rosenquist, A.; Hølmer, G. Regiospecific analysis of triacylglycerols using allyl magnesium bromide. Lipids 1993, 28, 147-149. [CrossRef]

26. Destaillats, F.; Angers, P.; Wolff, R.L.; Arul, J. Regiospecific analysis of conifer seed triacylglycerols by gas-liquid chromatography with particular emphasis on $\Delta 5$-olefinic acids. Lipids 2001, 36, 1247-1254. [CrossRef] 
27. Hashidate, T.; Itabashi, Y. Electrospray ionization mass spectrometry of regioisomeric 1,2-diacylglycerols. Bunseki Kagaku 2005, 54, 807-816. [CrossRef]

28. Itabashi, Y.; Myher, J.J.; Kuksis, A. Determination of positional distribution of short-chain fatty acids in bovine milk fat on chiral columns. JAOCS 1993, 70, 1177-1181. [CrossRef]

29. Morris, L.J. Separation of Lipids by Silver Ion Chromatography. J. Lipid Res. 1966, 7, 717-732. [CrossRef]

30. Nikolova-Damyanova, B. Silver Ion Chromatography and Lipids. In Advances in Lipid Methodology-One; Christle, W.W., Ed.; The Oily Press: Ayr, Scotland, 1992; pp. 181-237.

31. Momchilova, S.; Nikolova-Damyanova, B. TLC of lipids. In Thin Layer Chromatography in Phytochemistry; Waksmundzka-Hajnos, M., Sherma, J., Kowalska, T., Eds.; CRC Press: Boca Raton, FL, USA, 2008; pp. 277-297.

32. Momchilova, S.; Nikolova-Damyanova, B. Advances in Silver Ion Chromatography for the Analysis of Fatty Acids and Triacylglycerols-2001 to 2011. Anal. Sci. 2012, 28, 837-844. [CrossRef]

33. Dobson, G.; Christie, W.W.; Nikolova-Damyanova, B. Silver ion chromatography of lipids and fatty acids. J. Chromatogr. B 1995, 671, 197-222. [CrossRef]

34. Nikolova-Damyanova, B. Retention of lipids in silver ion high-performance liquid chromatography: Facts and assumptions. J. Chromatogr. A 2009, 1216, 1815-1824. [CrossRef] [PubMed]

35. Blanck, M.L.; Verdino, B.; Privett, O.S. Determination of Triglyceride via Silver Nitrate-TLC. JAOCS 1965, 42, 87-90. [CrossRef]

36. Nikolova-Damyanova, B.; Chobanov, D.; Dimov, S. Separation of Isomeric Triacylglycerols by Silver Ion Thin-Layer Chromatography. J. Liq. Chromatogr. 1993, 16, 3997-4008. [CrossRef]

37. Momchilova, S.; Nikolova-Damyanova, B. Stationary phases for silver ion chromatography: Preparation and properties. J. Sep. Sci. 2003, 26, 261-270. [CrossRef]

38. Dallas, M.S.J.; Padley, F.B. Analysis of confectionery fats. I. Separation of triglycerides by silver nitrate thin-layer chromatography. Lebensm.-Wiss. Und-Technol. 1977, 10, 328-331.

39. Gegiou, D.; Georgouli, M. A rapid argentation TLC method for detection of reesterified oils in olive and olive-residue oils. JAOCS 1983, 60, 833-835. [CrossRef]

40. Christie, W.W. A stable silver-loaded column for the separation of lipids by high performance liquid chromatography. J. High Res. Chromatogr. 1987, 10, 148-150. [CrossRef]

41. Adlof, R.O. Analysis of triacylglycerol positional isomers by silver ion high performance liquid chromatography. J. High. Res. Chromatogr. 1995, 18, 105-107. [CrossRef]

42. Adlof, R.; List, G. Analysis of triglyceride isomers by silver-ion high-performance liquid chromatography: Effect of column temperature on retention times. J. Chromatogr. A 2004, 1046, 109-113. [CrossRef] [PubMed]

43. Jeffrey, B.S.J. Silver-Complexation Liquid Chromatography for Fast, High-Resolution Separations of Triacylglycerols. JAOCS 1991, 68, 289-293. [CrossRef]

44. Schuyl, P.J.W.; de Joode, T.; Vasconcellos, M.A.; Duchateau, G.S.M.J.E. Silver-phase high-performance liquid chromatographyelectrospray mass spectrometry of triacylglycerols. J. Chromatogr. A 1998, 810, 53-61. [CrossRef]

45. Lísa, M.; Denev, R.; Holčapek, M. Retention behavior of isomeric triacylglycerols in silver-ion HPLC: Effects of mobile phase composition and temperature. J. Sep. Sci. 2013, 36, 2888-2900. [CrossRef]

46. Santoro, V.; Dal Bello, F.; Aigotti, R.; Gastaldi, D.; Romaniello, F.; Forte, E.; Magni, M.; Baiocchi, C.; Medana, C. Characterization and determination of interesterification markers (triacylglycerol regioisomers) in confectionery oils by liquid chromatographymass spectrometry. Foods 2018, 7, 23. [CrossRef]

47. Nikolova-Damyanova, B.; Christie, W.W.; Herslöf, B.G. Retention properties of triacylglycerols on silver ion high-performance liquid chromatography. J. Chromatogr. A 1995, 694, 375-380. [CrossRef]

48. Christie, W.W. Separation of molecular species of triacylglycerols by high-performance liquid chromatography with a silver ion column. J. Chromatogr. A 1988, 454, 273-284. [CrossRef]

49. Holčapek, M.; Dvoráková, H.; Lísa, M.; Girón, A.J.; Sandrab, P.; Cvacka, J. Regioisomeric analysis of triacylglycerols using silver-ion liquid chromatography-atmospheric pressure chemical ionization mass spectrometry: Comparison of five different mass analyzers. J. Chromatogr. A 2010, 1217, 8186-8194. [CrossRef] [PubMed]

50. Nikolova-Damyanova, B. Lipid Analysis by silver ion Chromatography. In Advances in Lipid Methodology—Five; Adlof, R.O., Ed.; The Oily Press: Bridgwater, UK, 2003; pp. 43-123.

51. Wada, S.; Koizumi, C.; Nonaka, J. Analysis of Triglycerides of Soybean Oil by High-Performance Liquid Chromatography in Combination with Gas Liquid Chromatography. J. Jpn. Oil Chem. Soc. 1977, 26, 95-99. [CrossRef]

52. Nikolova-Damyanova, B. Reversed phase HPLC: General principles and application to fatty acids and triacylglycerols. In Advances in Lipid Methodology—Four; Christie, W.W., Ed.; The Oily Press: Bridgwater, UK, 1997; pp. 193-251.

53. Aitzetmüller, K. The progress in the high performance liquid chromatography of lipids. Prog. Lipid Res. 1982, 21, 171-193. [CrossRef]

54. Shukla, V.K.S. Recent advances in the high-performance liquid chromatography of lipids. Prog. Lipid Res. 1988, 27, 5-38. [CrossRef]

55. Laakso, P.; Christie, W.W. Chromatographic resolution of chiral diacylglycerol derivatives: Potential in the stereospecific analysis of triacyl-sn-glycerols. Lipids 1990, 25, 349-353. [CrossRef] [PubMed] 
56. Lin, J.-T.; Snyder, L.R.; McKeona, T.A. Prediction of relative retention times of triacylglycerols in nonaqueous reversed-phase high-performance liquid chromatography. J. Chromatogr. A 1998, 808, 43-49. [CrossRef]

57. Momchilova, S.; Itabashi, Y.; Nikolova-Damyanova, B.; Kuksis, A. Regioselective separation of isomeric triacylglycerols by reversed-phase high-performance liquid chromatography: Stationary phase and mobile phase effects. J. Sep. Sci. 2006, 29, 2578-2583. [CrossRef]

58. Mottram, H.R.; Crossman, Z.M.; Evershed, R.P. Regiospecific characterisation of the triacylglycerols in animal fats using high performance liquid chromatography-atmospheric pressure chemical ionisation mass spectrometry. Analyst 2001, 126, 1018-1024. [CrossRef]

59. Mottram, H.R.; Evershed, R.P. Structure analysis of triacylglycerol positional isomers using atmospheric pressure chemical ionisation mass spectrometry. Tetrahedron Lett. 1996, 37, 8593-8596. [CrossRef]

60. Mottram, H.R.; Woodbury, S.E.; Evershed, R.P. Identification of triacylglycerol positional isomers present in vegetable oils by high performance liquid chromatography/atmospheric pressure chemical ionization mass spectrometry. Rapid Commun. Mass Spectr. 1997, 11, 1240-1252. [CrossRef]

61. Byrdwell, W.G. ACI-MS in Lipid Analysis. In Advances in Lipid Methodology_Five; Adlof, R.O., Ed.; The Oily Press: Bridgwater, UK, 2003; pp. 171-253.

62. Byrdwell, W.C. Atmospheric pressure chemical ionization mass spectrometry for analysis of lipids. Lipids 2001, 36, 327-346. [CrossRef] [PubMed]

63. Rigano, F.; Tranchida, P.Q.; Dugo, P.; Mondello, L. High-performance liquid chromatography combined with electron ionization mass spectrometry: A review. TrAC-Trends Anal. Chem. 2019, 118, 112-122. [CrossRef]

64. Holčapek, M.; Jandera, P.; Zderadička, P.; Hrubá, L. Characterization of triacylglycerol and diacylglycerol composition of plant oils using high-performance liquid chromatography-atmospheric pressure chemical ionization mass spectrometry. J. Chromatogr. A 2003, 1010, 195-215. [CrossRef]

65. Lísa, M.; Holčapek, M.; Sovová, H. Comparison of various types of stationary phases in non-aqueous reversed-phase highperformance liquid chromatography-mass spectrometry of glycerolipids in blackcurrant oil and its enzymatic hydrolysis mixture. J. Chromatogr. A 2009, 1216, 8371-8378. [CrossRef] [PubMed]

66. ̌ezanka, T.; Pádrová, K.; Sigler, K. Regioisomeric and enantiomeric analysis of triacylglycerols. Anal. Biochem. 2017, 524, 3-12. [CrossRef]

67. Leskinen, H.M.; Suomela, J.-P.; Kallio, H.P. Quantification of triacylglycerol regioisomers by ultra-high-performance liquid chromatography and ammonia negative ion atmospheric pressure chemical ionization tandem mass spectrometry. Rapid Comm. Mass Spectr. 2010, 24, 1-5. [CrossRef]

68. Vítová, M.; Goecke, F.; Sigler, K.; Řezanka, T. Lipidomic analysis of the extremophilic red alga Galdieria sulphuraria in response to changes in pH. Algal Res. 2016, 13, 218-226. [CrossRef]

69. ̌ezanka, T.; Lukavský, J.; Sigler, K.; Nedbalová, L.; Vítová, M. Temperature dependence of production of structured triacylglycerols in the alga Trachydiscus minutus. Phytochem. 2015, 110, 37-45. [CrossRef]

70. Beccaria, M.; Costa, R.; Sullini, G.; Grasso, E.; Cacciola, F.; Dugo, P.; Mondello, L. Determination of the triacylglycerol fraction in fish oil by comprehensive liquid chromatography techniques with the support of gas chromatography and mass spectrometry data. Anal. Bioanal. Chem. 2015, 407, 5211-5225. [CrossRef]

71. Schreiberová, O.; Krulikovská, T.; Sigler, K.; Čejková, A.; Řezanka, T. RP-HPLC/MS-APCI analysis of branched chain TAG prepared by precursor-directed biosynthesis with Rhodococcus erythropolis. Lipids 2010, 45, 743-756. [CrossRef] [PubMed]

72. Řezanka, T.; Lukavský, J.; Nedbalová, L.; Kolouchová, I.; Sigler, K. Effect of starvation on the distribution of positional isomers and enantiomers of triacylglycerol in the diatom Phaeodactylum tricornutum. Phytochemistry 2012, 80, 17-27. [CrossRef] [PubMed]

73. Ǩezanka, T.; Nedbalová, L.; Sigler, K. Comparative analysis of triacylglycerols from different Stichococcus strains by RPHPLC/APCI-MS and chiral HPLC. J. Appl. Phycol. 2015, 27, 685-696. [CrossRef]

74. Řezanka, T.; Kolouchová, I.; Čejková, A.; Cajthaml, T.; Sigler, K. Identification of regioisomers and enantiomers of triacylglycerols in different yeasts using reversed- and chiral-phase LC-MS. J. Sep. Sci. 2013, 36, 3310-3320. [CrossRef]

75. Kofroňová, E.; Cvačka, J.; Jiroš, P.; Sýkora, D.; Valterová, I. Analysis of insect triacylglycerols using liquid chromatographyatmospheric pressure chemical ionization-mass spectrometry. Eur. J. Lipid Sci. Technol. 2009, 111, 519-525. [CrossRef]

76. Holčapek, M.; Lísa, M.; Jandera, P.; Kabátová, N. Quantitation of triacylglycerols in plant oils using HPLC with APCI-MS, evaporative light-scattering, and UV detection. J. Sep. Sci. 2005, 28, 1315-1333. [CrossRef]

77. Lísa, M.; Lynen, F.; Holčapek, M.; Sandra, P. Quantitation of triacylglycerols from plant oils using charged aerosol detection with gradient compensation. J. Chromatogr. A 2007, 1176, 135-142. [CrossRef] [PubMed]

78. Ovčačíková, M.; Lísa, M.; Cífková, E.; Holčapek, M. Retention behavior of lipids in reversed-phase ultrahigh-performance liquid chromatography-electrospray ionization mass spectrometry. J. Chromatogr. A 2016, 1450, 76-85. [CrossRef]

79. Palyzová, A.; Cajthaml, T.; Řezanka, T. Separation of regioisomers and enantiomers of triacylglycerols containing branched fatty acids (iso and/or anteiso). Electrophoresis 2020, 42, 1832-1843. [CrossRef]

80. Kallio, H.; Yli-Jokipii, K.; Kurvinen, J.P.; Sjövall, O.; Tahvonen, R. Regioisomerism of triacylglycerols in lard, tallow, yolk, chicken skin, palm oil, palm olein, palm stearin, and a transesterified blend of palm stearin and coconut oil analyzed by tandem mass spectrometry. J. Agric. Food Chem. 2001, 49, 3363-3369. [CrossRef] 
81. Kallio, H.; Nylund, M.; Boström, P.; Yang, B. Triacylglycerol regioisomers in human milk resolved with an algorithmic novel electrospray ionization tandem mass spectrometry method. Food Chem. 2017, 233, 351-360. [CrossRef]

82. Herrera, L.C.; Ramaley, L.; Potvin, M.A.; Melanson, J.E. A method for determining regioisomer abundances of polyunsaturated triacylglycerols in omega-3 enriched fish oils using reversed-phase liquid chromatography and triple-stage mass spectrometry. Food Chem. 2013, 139, 655-662. [CrossRef] [PubMed]

83. Šala, M.; Lísa, M.; Campbell, J.L.; Holčapek, M. Determination of triacylglycerol regioisomers using differential mobility spectrometry. Rapid Commun. Mass Spectr. 2016, 30, 256-264. [CrossRef]

84. Dugo, P.; Kumm, T.; Chiofalo, B.; Cotroneo, A.; Mondello, L. Separation of triacylglycerols in a complex lipidic matrix by using comprehensive two-dimensional liquid chromatography coupled with atmosheric pressure chemical ionization mass spectrometric detection. J. Sep. Sci. 2006, 29, 1146-1154. [CrossRef]

85. Cacciola, F.; Dugo, P.; Mondello, L. Multidimensional liquid chromatography in food analysis. TrAC-Trends Anal. Chem. 2017, 96, 116-123. [CrossRef]

86. Cacciola, F.; Russo, M.; Mondello, L.; Dugo, P. Comprehensive Two-Dimensional Liquid Chromatography Coupled to Mass Spectrometry: Fundamentals, Method Development and Applications. Compr. Anal. Chem. 2018, 79, 81-123. [CrossRef]

87. Rigano, F.; Arigò, A.; Oteri, M.; la Tella, R.; Dugo, P.; Mondello, L. The Retention Index Approach in Liquid Chromatography: An Historical Review and Recent Advances. J. Chromatogr. A 2021, 1640, 461963. [CrossRef]

88. Kalpio, M.; Linderborg, K.M.; Fabritius, M.; Kallio, H.; Yang, B. Strategy for stereospecific characterization of natural triacylglycerols using multidimensional chromatography and mass spectrometry. J. Chromatogr. A 2021, 1641, 461992. [CrossRef]

89. Stoll, D.R.; Li, X.; Wang, X.; Carr, P.W.; Porter, S.E.G.; Rutan, S.C. Fast, comprehensive two-dimensional liquid chromatography. J. Chromatogr. A 2007, 1168, 3-43. [CrossRef]

90. Guiochon, G.; Marchetti, N.; Mriziq, K.; Shalliker, R.A. Implementations of two-dimensional liquid chromatography. J. Chromatogr. A 2008, 1189, 109-168. [CrossRef]

91. Dugo, P.; Favoino, O.; Tranchida, P.Q.; Dugo, G.; Mondello, L. Off-line coupling of non-aqueous reversed-phase and silver ion high-performance liquid chromatography-mass spectrometry for the characterization of rice oil triacylglycerol positional isomers. J. Chromatogr. A 2004, 1041, 135-142. [CrossRef]

92. Palyzová, A.; Řezanka, T. Separation and identification of diacylglycerols containing branched chain fatty acids by liquid chromatography-mass spectrometry. J. Chromatogr. A 2021, 1635, 461708. [CrossRef]

93. King, J.W. Supercritical fluid chromatography (SFC - global perspective and application in lipid analysis. In Advances in Lipid Methodology_Five; Adlof, R.O., Ed.; The Oily Press: Bridgwater, UK, 2003; pp. 301-353.

94. Duval, J.; Colas, C.; Pecher, V.; Poujol, M.; Tranchant, J.-F.; Lesellier, E. Hyphenation of ultra high performance supercritical fluid chromatography with atmospheric pressure chemical ionisation high resolution mass spectrometry: Part 1 . Study of the coupling parameters for the analysis of natural non-polar compounds. J. Chromatogr. A 2017, 1509, 132-140. [CrossRef] [PubMed]

95. Duval, J.; Colas, C.; Bonnet, P.; Lesellier, E. Hyphenation of ultra-high performance supercritical fluid chromatography with atmospheric pressure chemical ionisation high resolution mass spectrometry: Part 2. Study of chromatographic and mass spectrometry parameters for the analysis of natural non-polar compounds. J. Chromatogr. A 2019, 1596, 199-208. [CrossRef]

96. Donato, P.; Inferrera, V.; Sciarrone, D.; Mondello, L. Supercritical fluid chromatography for lipid analysis in foodstuffs. J. Sep. Sci. 2017, 40, 361-382. [CrossRef] [PubMed]

97. Masuda, K.; Abe, K.; Murano, Y.A. Practical Method for Analysis of Triacylglycerol Isomers Using Supercritical Fluid Chromatography. J. Am. Oil Chem. Soc. 2021, 98, 21-29. [CrossRef]

98. Lee, J.W.; Nagai, T.; Gotoh, N.; Fukusaki, E.; Bamba, T. Profiling of regioisomeric triacylglycerols in edible oils by supercritical fluid chromatography/tandem mass spectrometry. J. Chromatogr. B 2014, 966, 193-199. [CrossRef] [PubMed]

99. Ryhage, R.; Stenhagen, E. Mass spectrometry in lipid research. J. Lipid Res. 1960, 1, 361-390. [CrossRef]

100. Kallio, H.; Currie, G. Analysis of low erucic-acid turnip rapeseed oil (Brassica campestris) by negative ion chemical ionization tandem mass spectrometry. A method giving information on the fatty acid composition in positions sn-2 and sn-1/3 of triacylglycerols. Lipids 1993, 28, 207-215. [CrossRef]

101. Currie, G.J.; Kallio, H. Triacylglycerols of human milk: Rapid analysis by ammonia negative ion tandem mass spectrometry. Lipids 1993, 28, 217-222. [CrossRef]

102. Kallio, H.; Rua, P. Distribution of the Major Fatty Acids of Human Milk Between sn-2 and sn-1/3 Positions of Triacylglycerols. JAOCS 1994, 71, 985-992. [CrossRef]

103. Laakso, P.; Kallio, H. Optimization of the mass spectrometric analysis of triacylglycerols using negative-ion chemical ionization with ammonia. Lipids 1996, 31, 33-42. [CrossRef]

104. Kurvinen, J.-P.; Rua, P.; Sjövall, O.; Kallio, H. Software (MSPECTRA) for automatic interpretation of triacylglycerol molecular mass distribution spectra and collision induced dissociation product ion spectra obtained by ammonia negative ion chemical ionization mass spectrometry. Rapid Commun. Mass Spectr. 2001, 15, 1084-1091. [CrossRef]

105. Kurvinen, J.-P.; Mu, H.; Kallio, H.; Xu, X.; Høy, C.E. Regioisomers of octanoic acid-containing structured triacylglycerols analyzed by tandem mass spectrometry using ammonia negative ion chemical ionization. Lipids 2001, 36, 1377-1382. [CrossRef]

106. Kurvinen, J.-P.; Sjövall, O.; Kallio, H. Molecular Weight Distribution and Regioisomeric Structure of Triacylglycerols in Some Common Human Milk Substitutes. JAOCS 2002, 79, 13-22. [CrossRef] 
107. Malone, M.; Evans, J.J. Determining the Relative Amounts of Positional Isomers in Complex Mixtures of Triglycerides Using Reversed-Phase High-Performance Liquid Chromatography-Tandem Mass Spectrometry. Lipids 2004, 39, 273-284. [CrossRef] [PubMed]

108. Ramaley, L.; Cubero Herrera, L.; Melanson, J.E. Applicability of non-linear versus linear fractional abundance calibration plots for the quantitative determination of triacylglycerol regioisomers by tandem mass spectrometry. Rapid Commun. Mass Spectrom. 2013, 27, 1251-1259. [CrossRef]

109. Lin, J.-T.; Arcinas, A. Analysis of Regiospecific Triacylglycerols by Electrospray Ionization-Mass Spectrometry3 of Lithiated Adducts. J. Agric. Food Chem. 2008, 56, 4909-4915. [CrossRef] [PubMed]

110. Lin, J.-T. Ratios of Regioisomers of Triacylglycerols Containing Dihydroxy Fatty Acids in Castor Oil by Mass Spectrometry. JAOCS 2009, 86, 1031-1035. [CrossRef]

111. Lin, J.-T.; Fagerquist, C.K.; Chen, G.Q. Ratios of Regioisomers of the Molecular Species of Triacylglycerols in Lesquerella (Physaria fendleri) Oil Estimated by Mass Spectrometry. JAOCS 2016, 2, 183-191. [CrossRef]

112. Loutelier-Bourhis, C.; Zovi, O.; Lecamp, L.; Bunel, C.; Lange, C.M. Contribution of two approaches using electrospray ionization with multi-stage mass spectrometry for the characterization of linseed oil. Rapid Commun. Mass Spectr. 2009, 23, 3743-3752. [CrossRef]

113. Fasciotti, M.; Monteiro, T.V.C.; Rocha, W.F.C.; Moraes, L.R.; Sussulini, A.; Eberlin, M.N.; Cunha, V.S. Comprehensive Triacylglycerol Characterization of Oils and Butters of 15 Amazonian Oleaginous Species by ESI-HRMS/MS and Comparison with Common Edible Oils and Fats. Eur. J. Lipid Sci. Technol. 2020, 122, 2000019. [CrossRef]

114. Byrdwell, W.C. Qualitative and quantitative analysis of triacylglycerols by atmospheric pressure ionization (APCI and ESI) mass spectrometry techniques. In Modern Methods for Lipid Analysis by Liquid Chromatography/Mass Spectrometry and Related Techniques; Byrdwell, W.C., Ed.; AOCS Press: New York, NY, USA, 2005; pp. 298-412.

115. Byrdwell, W.C. The bottom-up solution to the triacylglycerol lipidome using atmospheric pressure chemical ionization mass spectrometry. Lipids 2005, 40, 383-417. [CrossRef] [PubMed]

116. Byrdwell, W.C. Critical Ratios for structural analysis of triacylglycerols using mass spectrometry. Lipid Technol. 2015, 27, 258-261. [CrossRef]

117. Byrdwell, W.C. The Updated Bottom Up Solution applied to mass spectrometry of soybean oil in a dietary supplement gelcap. Anal. Bioanal. Chem. 2015, 407, 5143-5160. [CrossRef]

118. Murphy, R.C. Challenges in mass spectrometry-based lipidomics of neutral lipids. TrAC-Trends Anal. Chem. 2018, 107, 91-98 [CrossRef]

119. Fabritius, M.; Linderborg, K.M.; Tarvainen, M.; Kalpio, M.; Zhang, Y.; Yang, B. Direct inlet negative ion chemical ionization tandem mass spectrometric analysis of triacylglycerol regioisomers in human milk and infant formulas. Food Chem. 2020, 328, 126991. [CrossRef]

120. Yeo, J.D.; Parrish, C.C. Evaluation of triacylglycerol (TAG) profiles and their contents in salmon muscle tissue using ESI-MS/MS spectrometry with multiple neutral loss scans. Food Chem. 2020, 324, 126816. [CrossRef]

121. Leveque, N.L.; Acheampong, A.; Heron, S.; Tchapla, A. Determination of triacylglycerol regioisomers using electrospray ionization-quadrupole ion trap mass spectrometry with a kinetic method. Anal. Chim. Acta 2012, 722, 80-86. [CrossRef]

122. Jie, M.S.L.K.; Lam, C.C. 13C-Nuclear magnetic resonance spectroscopic studies of triacylglycerols of type AAA containing (Z)and (E)-monoethylenic acyl groups. Chem. Phys. Lipids 1995, 78, 15-27. [CrossRef]

123. Redden, P.R.; Lin, X.; Horrobin, D.F. Comparison of the Grignard deacylation TLC and HPLC methods and high resolution 13C-NMR for the sn-2 positional analysis of triacylglycerols containing $\gamma$-linolenic acid. Chem. Phys. Lipids 1996, 79, 9-19. [CrossRef]

124. Vlahov, G. Determination of the 1,3- and 2-positional distribution of fatty acids in olive oil triacylglycerols by $13 \mathrm{C}$ nuclear magnetic resonance spectroscopy. J. AOAC Intern. 2006, 89, 1071-1076. [CrossRef]

125. Kildahl-Andersen, G.; Gjerlaug-Enger, E.; Rise, F.; Haug, A.; Egelandsdal, B. Quantification of Fatty Acids and their Regioisomeric Distribution in Triacylglycerols from Porcine and Bovine Sources Using 13C NMR Spectroscopy. Lipids 2021, 56, 111-122. [CrossRef] [PubMed]

126. Andreotti, G.; Trivellone, E.; Lamanna, R.; Di Luccia, A.; Motta, A. Milk Identification of Different Species: 13C-NMR Spectroscopy of Triacylglycerols from Cows and Buffaloes' Milks. J. Dairy Sci. 2000, 83, 2432-2437. [CrossRef]

127. He, Y.; Wu, T.; Sun, H.; Sun, P.; Liu, B.; Luo, M.; Chen, F. Comparison of fatty acid composition and positional distribution of microalgae triacylglycerols for human milk fat substitutes. Algal Res. 2019, 37, 40-50. [CrossRef]

128. Quintanilla-Casas, B.; Strocchi, G.; Bustamante, J.; Torres-Cobos, B.; Guardiola, F.; Moreda, W.; Martínez-Rivas, J.M.; Valli, E.; Bendini, A.; Toschi, T.G.; et al. Large-scale evaluation of shotgun triacylglycerol profiling for the fast detection of olive oil adulteration. Food Control 2021, 123, 107851. [CrossRef]

129. Hancock, S.E.; Poad, B.L.J.; Batarseh, A.; Abbott, S.K.; Mitchell, T.W. Advances and unresolved challenges in the structural characterization of isomeric lipids. Anal. Biochem. 2017, 524, 45-55. [CrossRef]

130. Han, X.; Ye, H. Overview of Lipidomic Analysis of Triglyceride Molecular Species in Biological Lipid Extracts. J. Agric. Food Chem. 2021, 69, 8895-8909. [CrossRef] 
131. Christie, W.W.; Nikolova-Damyanova, B.; Laakso, P.; Herslof, B. Stereospecific analysis of triacyl-sn-glycerols via resolution of diastereomeric diacylglycerol derivatives by high-performance liquid chromatography on silica. JAOCS 1991, 68, 695-701. [CrossRef]

132. Takagi, T.; Itabashi, Y. Resolution of racemic monoacylglycerols to enantiomers by high-performance liquid chromatography. JAOCS 1985, 34, 962-963. [CrossRef]

133. Itabashi, Y.; Takagi, T. High performance liquid chromatographic separation of monoacylglycerol enantiomers on a chiral stationary phase. Lipids 1986, 21, 413-416. [CrossRef]

134. Takagi, T.; Ando, Y. Enantiomer separations of mixtures of monoacylglycerol derivatives by HPLC on a chiral column. Lipids 1990, 25, 398-400. [CrossRef]

135. Itabashi, Y.; Takagi, T. High-performance liquid chromatographic separation of diacylglycerol enantiomers on a chiral stationary phase. J. Chromatogr. A 1987, 402, 257-264. [CrossRef]

136. Itabashi, Y.; Kukis, A.; Marai, L.; Takagi, T. HPLC resolution of diacylglycerol moieties of natural triacylglycerols on a chiral phase consisting of bonded (R)-(+)-1-(1-naphthyl)ethylamine. J. Lipid Res. 1990, 31, 1711-1717. [CrossRef]

137. Itabashi, Y.; Kuksis, A.; Myher, J.J. Determination of molecular species of enantiomeric diacylglycerols by chiral phase high performance liquid chromatography and polar capillary gas-liquid chromatography. J. Lipid Res. 1990, 31, 2119-2126. [CrossRef]

138. Itabashi, Y.; Marai, L.; Kuksis, A. Identification of natural diacylglycerols as the 3,5-dinitrophenylurethanes by chiral phase liquid chromatography with mass spectrometry. Lipids 1991, 26, 951-956. [CrossRef]

139. Takagi, T.; Ando, Y. Stereospecific analysis of triacyl-sn-glycerols by chiral high-performance liquid chromatography. Lipids 1991, 26, 542-547. [CrossRef]

140. Ando, Y.; Takagi, T. Micro method for stereospecific analysis of triacyl-sn-glycerols by chiral-phase high performance liquid chromatography. JAOCS 1993, 70, 1047-1049. [CrossRef]

141. Itabashi, Y.; Myher, J.J.; Kuksis, A. High-performance liquid chromatographic resolution of reverse isomers of 1,2-diacyl-racglycerols as 3,5-dinitrophenylurethanes. J. Chromatogr. A 2000, 893, 261-279. [CrossRef]

142. Okabe, H.; Itabashi, Y.; Ota, T.; Kuksis, A. Highly sensitive method for the separation of enantiomeric and regioisomeric diacylglycerols as 2-anthrylurethanes by chiral-phase high-performance liquid chromatography with fluorescence detection. J. Chromatogr. A 1998, 829, 81-89. [CrossRef]

143. Itabashi, Y. Chiral-phase HPLC resolution of enantiomeric diacylglycerol moieties of fish-oil triacylglycerols. Bunseki Kagaku 1999, 48, 1145-1148. [CrossRef]

144. Christie, W.W. Positional distribution of fatty acids in glycerolipids. In Lipid Analysis, 3rd ed.; Christie, W.W., Ed.; The Oily Press: Bridgwater, UK, 2003; pp. 373-387.

145. Kalo, P. Regio- and stereospecific analysis of diacylglycerols and monoacylglycerols. Lipid Technol. 2014, 26, 63-66. [CrossRef]

146. Nagai, T.; Mizobe, H.; Otake, I.; Ichioka, K.; Kojima, K.; Matsumoto, Y.; Gotoh, N.; Kuroda, I.; Wada, S. Enantiomeric separation of asymmetric triacylglycerol by recycle high-performance liquid chromatography with chiral column. J. Chromatogr. A 2011, 1218, 2880-2886. [CrossRef]

147. Nagai, T.; Matsumoto, Y.; Jiang, Y.; Ishikawa, K.; Wakatabe, T.; Mizobe, H.; Yoshinaga, K.; Kojima, K.; Kuroda, I.; Saito, T.; et al. Actual ratios of triacylglycerol positional isomers and enantiomers comprising saturated fatty acids and highly unsaturated fatty acids in fishes and marine mammals. J. Oleo Sci. 2013, 62, 1009-1015. [CrossRef]

148. Nagai, T.; Watanabe, N.; Yoshinaga, K.; Mizobe, H.; Kojima, K.; Kuroda, I.; Odanaka, Y.; Saito, T.; Beppu, F.; Gotoh, N. Abundances of triacylglycerol positional isomers and enantiomers comprised of a dipalmitoylglycerol backbone and short- or medium-chain fatty acids in bovine milk fat. J. Oleo Sci. 2015, 64, 943-952. [CrossRef]

149. Gotoh, N.; Wada, S.; Nagai, T. Separation of asymmetric triacylglycerols into their enantiomers by recycle high-performance liquid chromatography. Lipid Technol. 2011, 23, 105-108. [CrossRef]

150. Kalpio, M.; Nylund, M.; Linderborg, K.M.; Yang, B.; Kristinsson, B.; Haraldsson, G.G.; Kallio, H. Enantioselective chromatography in analysis of triacylglycerols common in edible fats and oils. Food Chem. 2015, 172, 718-724. [CrossRef] [PubMed]

151. Kalpio, M.; Magnússon, J.D.; Gudmundsson, H.G.; Linderborg, K.M.; Kallio, H.; Haraldsson, G.G.; Yang, B. Synthesis and enantiospecific analysis of enantiostructured triacylglycerols containing n-3 polyunsaturated fatty acids. Chem. Phys. Lipids 2020, 231, 104937. [CrossRef] [PubMed]

152. Nagai, T.; Kinoshita, T.; Kasamatsu, E.; Yoshinaga, K.; Mizobe, H.; Yoshida, A.; Itabashi, Y.; Gotoh, N. Simultaneous separation of triacylglycerol enantiomers and positional isomers by chiral high performance liquid chromatography coupled with mass spectrometry. J. Oleo Sci. 2019, 68, 1019-1026. [CrossRef] [PubMed]

153. Nagai, T.; Kinoshita, T.; Kasamatsu, E.; Yoshinaga, K.; Mizobe, H.; Yoshida, A.; Itabashi, Y.; Gotoh, N. Simultaneous quantification of mixed-acid triacylglycerol positional isomers and enantiomers in palm oil and lard by chiral high-performance liquid chromatography coupled with mass spectrometry. Symmetry 2020, 12, 1385. [CrossRef]

154. Lísa, M.; Holčapek, M. Characterization of triacylglycerol enantiomers using chiral HPLC/APCI-MS and synthesis of enantiomeric triacylglycerols. Anal. Chem. 2013, 85, 1852-1859. [CrossRef] [PubMed]

155. Chen, Y.J.; Zhou, X.H.; Han, B.; Yu, Z.; Yi, H.X.; Jiang, S.L.; Li, Y.Y.; Pan, J.C.; Zhang, L.W. Regioisomeric and enantiomeric analysis of primary triglycerides in human milk by silver ion and chiral HPLC APCI-MS. J. Dairy Sci. 2020, 103, 7761-7774. [CrossRef]

156. Ǩezanka, T.; Lukavský, J.; Nedbalová, L.; Sigler, K. Production of structured triacylglycerols from microalgae. Phytochemistry 2014, 104, 95-104. [CrossRef] 
157. Ǩezanka, T.; Vítová, M.; Nováková, A.; Sigler, K. Separation and Identification of Odd Chain Triacylglycerols of the Protozoan Khawkinea quartana and the Mold Mortierella alpina Using LC-MS. Lipids 2015, 50, 811-820. [CrossRef]

158. Ǩezanka, T.; Nedbalová, L.; Sigler, K. Enantiomeric separation of triacylglycerols containing polyunsaturated fatty acids with 18 carbon atoms. J. Chromatogr. A 2016, 1467, 261-269. [CrossRef] [PubMed]

159. Řezanka, T.; Kolouchová, I.; Nedbalová, L.; Sigler, K. Enantiomeric separation of triacylglycerols containing very long chain fatty acids. J. Chromatogr. A 2018, 1557, 9-19. [CrossRef] [PubMed]

160. Palyzová, A.; Rezanka, T. Enantiomeric separation of triacylglycerols containing fatty acids with a ring (cyclofatty acids). J. Chromatogr. A 2020, 1622, 461103. [CrossRef]

161. Palyzová, A.; Rezanka, T. Separation of triacylglycerols containing allenic and acetylenic fatty acids by enantiomeric liquid chromatography-mass spectrometry. J. Chromatogr. A 2020, 1623, 461161. [CrossRef] [PubMed]

162. Yoshinaga, K. Development of Analytical Methods and Nutritional Studies Using Synthetic Fatty Acids and Triacylglycerols. J. Oleo Sci. 2021, 70, 1-9. [CrossRef]

163. Picq, M.; Bernoud-Hubac, N.; Lagarde, M. Synthesis and biological interest of structured docosahexaenoic acid-containing triacylglycerols and phospholipids. Org. Chem. 2013, 17, 841-847. [CrossRef] 